\title{
NEGAÇÃO, OCULTAMENTO E (FALTA DE) GESTÂO DOCUMENTAL: O ACESSO AOS ARQUIVOS NOS RELATÓRIOS FINAIS DAS COMISSÕES DA VERDADE NO BRASIL
}

\author{
DENIAL, CONCEALING, AND (LACK) OF ARCHIVES \\ MANAGEMENT: ARCHIVAL ACCESS IN THE FINAL \\ REPORTS OF TRUTH COMMISSIONS IN BRAZIL
}

Mônica Tenagliaa

Georgete Medleg Rodrigues ${ }^{b}$

\begin{abstract}
RESUMO
Introdução: As comissões da verdade têm sido consideradas um dos dispositivos mais importantes relacionados às investigações sobre violações de direitos humanos e o seu trabalho depende majoritariamente do acesso a grandes quantidades de documentos de arquivo. Objetivo: Esse artigo analisa as condições de pesquisa aos documentos de arquivo pelas comissões da verdade mediante a análise dos processos de acesso relatados nos relatórios finais. Metodologia: Foi realizado um levantamento das comissões da verdade instaladas no Brasil entre 2012 e 2018 e, em seguida, foram selecionadas aquelas que divulgaram seus relatórios finais e, nestes últimos, quais apresentaram as dificuldades de acesso aos arquivos. Resultados: Agrupadas de acordo com a concepção de acesso de Taylor (1984), constatou-se que as comissões da verdade no Brasil enfrentaram dificuldades de acesso legal, físico e intelectual aos arquivos, decorrentes da falta de colaboração, especialmente das Forças Armadas e das precárias condições de preservação dos documentos e ausência de instrumentos de pesquisa. Conclusões: Conclui-se que apesar da maior liberalidade de acesso aos arquivos, a partir dos anos de 1990, devido à Lei de Arquivos e por legislação específica que levou ao recolhimento dos acervos dos órgãos de repressão e, em 2011, a promulgação da Lei de Acesso à Informação (LAl), as condições de pesquisa documental sobre a ditadura militar brasileira (1964-1985) ainda permanecem precárias nas três dimensões destacadas por Taylor.
\end{abstract}

Descritores: Ditadura Militar Brasileira. Comissões da Verdade. Acesso.

\footnotetext{
a Doutora em Ciência da Informação pela Universidade de Brasília (UnB).

Professora voluntário da Universidade de Brasília (UnB). E-mail: motenaglia@hotmail.com

b Doutora em História Contemporânea pela Université de Paris. Professora do Programa de PósGraduação em Ciência da Informação da Universidade de Brasília (UnB). E-mail: medleg.georgete@gmail.com
} 


\section{INTRODUÇÃO}

Desde a década de 1980, as comissões da verdade têm sido consideradas um dos dispositivos mais importantes para as investigações sobre violações de direitos humanos no mundo. A emergência das comissões da verdade remonta à necessidade de lidar com o legado de violações de direitos humanos e injustiça ocorridos durante regimes repressivos. Na América Latina, elas foram criadas pelos países que estiveram sob ditaduras militares e guerras civis; na Europa Central e do Leste, foram instituídas nos países que constituíram o bloco soviético; e no continente africano, foram criadas pelos países que estiveram sob regimes repressivos baseados na segregação racial (QUINTANA, 2009).

Embora seja difícil quantificar o número de comissões da verdade já criadas, é possível afirmar que mais de quarenta comissões da verdade foram instituídas em todos os continentes, e mais da metade delas nos últimos quinze anos (CHAPMAN; BALL, 2001; HAYNER, 2006, 2011; JONES; OLIVEIRA, 2016; BRAHM, 2009).

Entre os estudiosos do assunto, uma das definições mais utilizadas sobre comissões da verdade é a de Priscilla Hayner, segundo a qual:

[...] uma comissão da verdade (1) está focada no passado, ao invés de eventos ainda em curso; (2) investiga um padrão de eventos que ocorreram num determinado período; (3) envolvese direta e amplamente com a população afetada, coletando informações sobre suas experiências; (4) é um órgão temporário, com o objetivo de concluir com um relatório final; e (5) é oficialmente autorizada pelo Estado (HAYNER, 2011, p. 12, tradução nossa).

No Brasil, a Lei n. 12.528, de 18 de novembro de 2011, criou a Comissão Nacional da Verdade (CNV). A lei, por meio do seu artigo Art. $4^{\circ}$, Inciso VII, também estabeleceu que a CNV poderia promover parcerias com órgãos públicos e privados para o intercâmbio de informações. Esse dispositivo permitiu a inauguração de um fenômeno único internacionalmente, que foi a instalação de comissões da verdade nos estados, municípios, universidades, e em representações profissionais e de entidades. Expressivo entre 2012 e 2016, esse fenômeno, chamado de "comissionismo" por Hollanda (2018), ultrapassou a 
iniciativa da própria CNV que, em seu relatório final, segundo Hollanda (2018), "sequer foi capaz de identificar o número exato de comissões dedicadas à 'busca da verdade', limitando-se a uma estimativa: elas somariam, naquela altura, cerca de cem em todo país" (HOLLANDA, 2018, p. 3).

Paralelamente à aprovação da lei de criação da CNV, foi promulgada a Lei n. 12.527/2011, mais conhecida como Lei de Acesso à Informação (LAl). Com o objetivo de regulamentar o acesso público às informações e o direito à informação previstos na Constituição Federal de 1988, a LAI, no art. 21, também determina que informações ou documentos que versem sobre violações de direitos humanos não podem ser objeto de restrição de acesso ou destruição.

O papel investigativo das comissões da verdade depende majoritariamente do acesso a grandes quantidades de documentos de arquivo, a fim de descobrir e clarificar as ocorrências de graves violações de direitos humanos e sugerir recomendações para que esses crimes não aconteçam novamente.

Nesse sentido, mais de duas décadas de espera, contadas a partir do fim da ditadura militar brasileira (1964-1985) renderam, às comissões da verdade no Brasil, um aparato jurídico e um acervo documental que deveriam, em teoria, facilitar os trabalhos de investigação sobre as violações de direitos humanos durante a ditadura militar. No aspecto jurídico, nos referimos à criação da LAl; quanto ao acervo documental, lembramos da existência de centenas de fundos arquivísticos sobre a ditadura militar, recolhidos aos arquivos públicos de diversas regiões do país, desde o desmonte das polícias políticas e dos órgãos de informação, desde o final dos anos 1980, e, em especial, nos anos 1990. ${ }^{1}$ Além disso, em 2005, por meio de decreto presidencial, ocorreu o recolhimento, à Coordenação Regional do Arquivo Nacional (Coreg), em Brasília, dos acervos dos extintos Serviço Nacional de Informações (SNI), do Conselho de Segurança Nacional (CSN) e da Comissão Geral de Investigações (CGI), constituindo-se "num marco importante em direção à abertura dos arquivos da ditadura produzidos pelos órgãos que atuaram na repressão durante o regime militar"

\footnotetext{
1 Um dossiê sobre o tema do recolhimento ao acesso a esses acervos foi tema do número 1 da revista Quadrilátero, publicada pelo Arquivo Público do Distrito Federal em 1998.
} 
(ISHAQ, 2016, p. 113). Somada a essas iniciativas, foi criado, em 2009, o Projeto Memórias Reveladas², no Arquivo Nacional.

Essas constatações, aliadas a uma revisão de literatura sobre o tema, guiaram a principal questão investigada nesse artigo, ou seja, quais foram as condições enfrentadas pelas comissões da verdade no Brasil quanto ao acesso (físico, intelectual e legal) aos documentos de arquivo?

Parte de uma pesquisa de doutorado em Ciência da Informação, em fase de conclusão, sobre a relação das comissões da verdade com os arquivos da ditadura militar, o objetivo desse estudo é analisar quais foram as dificuldades de utilização e acesso aos arquivos apresentadas nos relatórios finais das comissões da verdade durante as investigações sobre as graves violações de direitos humanos ocorridas na ditadura militar.

Como ponto de partida teórico, utilizaremos a definição de acesso aos documentos arquivísticos apresentada por Hugh Taylor (1984), em estudo encomendado pela UNESCO, e que será o aporte para a reflexão crítica dos resultados do estudo. Com base no estudo dos usuários de arquivo, Taylor define três dimensões para o acesso: a) físico - relacionado ao recolhimento e avaliação dos documentos arquivísticos; b) intelectual - relacionado aos instrumentos de pesquisa e disponibilização; c) legal - relacionado aos aspectos jurídicos que envolvem restrição e acesso.

Considerando que o fenômeno da criação de comissões da verdade aconteceu em período relativamente recente no Brasil (com algumas ainda em funcionamento), o estudo justifica-se pela relevância das investigações sobre as graves violações de direitos humanos cometidas pelo Estado brasileiro. Além disso, constatamos também uma lacuna nas pesquisas no campo da Ciência da Informação sobre as comissões da verdade e uso dos arquivos em suas investigações e o fato de que aquelas que identificamos não abordam os aspectos que estudamos ${ }^{3}$.

2 O Centro de Referência das Lutas Políticas no Brasil, denominado 'Memórias Reveladas', foi instituído em 2009 com a finalidade de reunir informações sobre a ditadura militar brasileira em acervos públicos e privados.

${ }^{3}$ Nas Consultas no Banco de Teses e Dissertações da CAPES e no portal de eventos da ANCIB (Associação Nacional de Pesquisa e Pós-Graduação em Ciência da Informação), encontramos a dissertação de mestrado "Comissão da Verdade: os documentos e a validez do discurso" de 
O artigo está estruturado em três partes, da seguinte forma: os procedimentos metodológicos adotados para a realização do estudo; a relação das comissões da verdade com os arquivos, as dificuldades relatadas e os resultados; e, por fim, as considerações finais.

\section{PROCEDIMENTOS METODOLÓGICOS}

Para atingir o objetivo proposto, utilizamos método de levantamento para mapear as comissões da verdade criadas no Brasil entre 2012 e 2018, totalizando oitenta e oito (88) comissões. Desse total, foi possível identificar vinte (20) relatórios finais publicados na internet que descreveram problemas relacionados à utilização dos arquivos nas suas investigações, constituindo, assim, o nosso universo de pesquisa. Apresentadas de diversas maneiras, em meio aos relatos de busca por informações sobre casos específicos/emblemáticos, ou relacionando-as às experiências de uso de documentos em instituições arquivísticas específicas, essas dificuldades, como um todo, constituem uma representação bastante fidedigna da realidade dos arquivos brasileiros com a qual estamos familiarizados nas últimas décadas: a negação da existência dos arquivos da ditadura militar, o ocultamento desses

Dayo Côrbo (CÔRBO; 2013); as comunicações apresentadas no ENANCIB: em 2013, "Comissão da verdade: os documentos e a verdade", de Dayo Côrbo e Clóvis Montenegro de Lima (CÔRBO; LIMA, 2013) e "A rede informacional franco-brasileira durante a ditadura militar no Brasil", de Ricardo Pimenta (PIMENTA, 2013); em 2016, "O documento como objeto e elo interdisciplinar na ciência da informação", de Dayo Côrbo e Ricardo Pimenta (CÔRBO; PIMENTA, 2016). Recentemente, no Encontro Nacional de Pesquisa em Ciência da Informação (ENANCIB), de 2018, maior congresso da área, realizado em Londrina-PR, foram apresentados apenas cinco trabalhos sobre a temática de direitos humanos e apenas dois trabalhos específicos às comissões da verdade. Foram eles: A dimensão da informação no âmbito de organizações internacionais de direitos humanos: abordagens possíveis", de Pedro Alves Barbosa Neto; 2) "Sítios de memória e direitos humanos da América Latina: arquivos, bibliotecas, museus e centros de documentação", de Mariana Ramos Crivelente e Nair Yumiko Kobashi; 3) "As questões de memória e os direitos humanos", de Caroline Teixeira da Silva Polli e Letícia Gorri Molina; 4) "Comissões da verdade brasileiras: das dificuldades de acesso aos arquivos às parcerias com as universidades", de Mônica Tenaglia e Georgete Medleg Rodrigues, e 5) "A comissão da verdade de Minas Gerais : uma análise das recomendações do relatório final sobre o pilar da memória e verdade", de Ana Cláudia Ribeiro, Maria Guiomar da Cunha Frota e Pablo Gomes. Para os anais do ENANCIB 2018, ver:

<http://enancib.marilia.unesp.br/index.php/XIXENANCIB/xixenancib/schedConf/presentations>. Acesso em 13 fev. 2019. 
acervos e a falta de gestão de documentos ${ }^{4}$.

Dessa maneira, utilizando a concepção de acesso aos documentos arquivísticos definida por Taylor (1984), segundo o qual o acesso é concebido em três dimensões - legal, físico e intelectual - conforme destacado anteriormente, agrupamos as dificuldades identificadas nos relatórios finais, conforme o Quadro 1:

\section{Quadro 1 - As dificuldades de acesso aos arquivos de acordo com as comissões da verdade.}

\begin{tabular}{|c|c|c|c|c|}
\hline \multirow[t]{2}{*}{ N. } & \multirow[t]{2}{*}{ Nome } & \multicolumn{3}{|c|}{ Acesso } \\
\hline & & Legal & Físico & Intelectual \\
\hline 1 & Comissão Nacional da Verdade & $\mathrm{X}$ & & \\
\hline 2 & Comissão Estadual da Verdade do Amapá & $\mathrm{X}$ & $\mathrm{X}$ & $\mathrm{X}$ \\
\hline 3 & Comissão Estadual da Verdade da Bahia & $X$ & $\mathrm{X}$ & $X$ \\
\hline 4 & Comissão Estadual da Verdade da Paraíba & $\mathrm{X}$ & $\mathrm{X}$ & $\mathrm{X}$ \\
\hline 5 & $\begin{array}{l}\text { Comissão Estadual da } \text { Verdade de } \\
\text { Pernambuco }\end{array}$ & $\mathrm{X}$ & & \\
\hline 6 & Comissão Estadual da Verdade do Paraná & $\mathrm{X}$ & & $\mathrm{X}$ \\
\hline 7 & $\begin{array}{l}\text { Comissão Estadual da Verdade de Santa } \\
\text { Catarina }\end{array}$ & & $\mathrm{X}$ & \\
\hline 8 & $\begin{array}{l}\text { Comissão Estadual da Verdade de Minas } \\
\text { Gerais }\end{array}$ & $\mathrm{X}$ & $\mathrm{X}$ & $\mathrm{X}$ \\
\hline 9 & $\begin{array}{l}\text { Comissão Estadual da Verdade do Rio de } \\
\text { Janeiro }\end{array}$ & $\mathrm{X}$ & $\mathrm{X}$ & $\mathrm{X}$ \\
\hline 10 & $\begin{array}{l}\text { Comissão Estadual da Verdade de São } \\
\text { Paulo }\end{array}$ & $\bar{X}$ & $\mathrm{X}$ & $\bar{X}$ \\
\hline 11 & $\begin{array}{l}\text { Comissão Municipal da Verdade de } \\
\text { Guarulhos }\end{array}$ & $\mathrm{X}$ & $\mathrm{X}$ & \\
\hline 12 & $\begin{array}{l}\text { Comissão Municipal da Verdade de Juiz de } \\
\text { Fora }\end{array}$ & $\mathrm{X}$ & $\mathrm{X}$ & $\mathrm{X}$ \\
\hline 13 & $\begin{array}{l}\text { Comissão da Verdade da Prefeitura de São } \\
\text { Paulo }\end{array}$ & & $\mathrm{X}$ & $\mathrm{X}$ \\
\hline 14 & $\begin{array}{l}\text { Comissão Municipal da Verdade de Volta } \\
\text { Redonda }\end{array}$ & $\mathrm{X}$ & & $\mathrm{X}$ \\
\hline 15 & $\begin{array}{l}\text { Comissão da Verdade da Universidade } \\
\text { Federal do Rio Grande do Norte (UFRN) }\end{array}$ & $\mathrm{X}$ & $\mathrm{X}$ & $\mathrm{X}$ \\
\hline 16 & $\begin{array}{l}\text { Comissão da Verdade da Universidade } \\
\text { Federal do Espírito Santo (UFes) }\end{array}$ & & $\mathrm{X}$ & $\mathrm{X}$ \\
\hline 17 & $\begin{array}{l}\text { Comissão da Verdade da Universidade de } \\
\text { Brasília (UnB) }\end{array}$ & $\mathrm{X}$ & $\mathrm{X}$ & \\
\hline 18 & $\begin{array}{l}\text { Comissão da Verdade da Universidade de } \\
\text { São Paulo (USP) }\end{array}$ & $\mathrm{X}$ & $\mathrm{X}$ & $\mathrm{X}$ \\
\hline 19 & Comissão Camponesa da Verdade & $\mathrm{X}$ & $\mathrm{X}$ & $\mathrm{X}$ \\
\hline
\end{tabular}

${ }^{4}$ Segundo o Dicionário Brasileiro de Terminologia Arquivística, a gestão de documentos é o "conjunto de procedimentos e operações técnicas referentes à produção, tramitação, tramitação uso, avaliação e avaliação e arquivamento" (ARQUIVO NACIONAL, 2005, p. 100). 
20 Comissão da Verdade da Central Única dos Trabalhadores (CUT)

Fonte: Os autores

\section{AS DIFICULDADES DE ACESSO AOS ARQUIVOS PELAS COMISSÕES DA VERDADE NO BRASIL: NEGAÇÃO, OCULTAMENTO E FALTA DE GESTÃO DE DOCUMENTOS}

Embora, de acordo com o Art. $4^{\circ}$ da Lei n. 12.528/2011, que criou a CNV, a comissão poderia: "II - Requisitar informações, dados e documentos de órgãos e entidades do poder público, ainda que classificados em qualquer grau de sigilo", e ainda, que: "§ $3^{\circ}$ : É dever dos servidores públicos e dos militares colaborar com a Comissão Nacional da Verdade" (BRASIL, 2011b, não paginado), na prática, as relações da CNV com as Forças Armadas foram bem diferentes, assim como foram as experiências de acesso aos arquivos pelas comissões da verdade locais, que esbarraram na resistência, não somente por parte dos comandos militares, mas também de instituições públicas e privadas, indo ao encontro do que afirma Rodrigues (2011): "a tradição brasileira em relação ao acesso aos arquivos assenta-se, preferencialmente, na "salvaguarda" das informações, o que se traduz, na verdade, pela ênfase no sigilo" (RODRIGUES, 2011, p. 280).

No entanto, o discurso oficial das Forças Armadas, baseado na "negação" ou "ocultamento" dos documentos não é peculiar ao Brasil. Segundo mostram Thiesen et al. (2017), após o retorno à democracia, nos países do chamado Cone Sul (Argentina, Bolívia, Brasil, Chile, Paraguai e Uruguai), as respostas, especialmente das Forças Armadas, aos pedidos de acesso aos arquivos pelos familiares de mortos e desaparecidos políticos, e pesquisadores, sempre incidiram sobre a "NEGAÇÃO (da existência dos arquivos) ou o OCULTAMENTO (RESTRIÇÃO DE ACESSO ou DESTRUIÇÃO DOS ARQUIVOS)" (THIESEN et al., 2017, p. 363).

Além das dificuldades de acesso aos arquivos em consequência da resistência e falta de colaboração do Ministério da Defesa, Forças Armadas e instituições públicas e privadas, as comissões da verdade no Brasil esbarraram 
nas dificuldades decorrentes da desorganização dos documentos arquivísticos. Apesar de contar com mais de 20 milhões de páginas produzidas/acumuladas pelos órgãos repressivos recolhidos ao Arquivo Nacional, além de outros acervos transferidos aos arquivos públicos estaduais, constituindo uma disponibilidade de informações que, segundo o relatório final da CNV, "não encontra paralelo em nenhum outro país" (BRASIL, 2014, p. 22), as comissões da verdade locais relataram entraves relacionados à falta de preservação, conservação, organização, classificação e digitalização dos documentos arquivísticos, decorrentes da falta de políticas e gestão dos arquivos governamentais. Como nos lembra Joffily (2012):

\begin{abstract}
A questão do acesso à informação, seja por razões probatórias, para fins de pesquisas científicas ou averiguações jornalísticas, vai além da desclassificação dos documentos sigilosos. Passa por uma política de disponibilização consistente das massas documentais liberadas, o que inclui um esforço de monta para organizar, conservar e tratar esses acervos, bem como para elaborar instrumentos de busca adequados [...] (JOFFILY, 2012, p. 139, grifos nossos).
\end{abstract}

\title{
3.1 A Negação e Ocultamento de Documentos: As Dificuldades de ACESSO INTELECTUAL AOS ARQUIVOS
}

Aprovada concomitantemente à lei de criação da CNV, a LAI, cujo objetivo é regulamentar o direito à informação e à privacidade, previstos na Constituição Federal de 1988, e garantir maior transparência à administração pública, também determina que informações ou documentos que versem sobre violações de direitos humanos pelo Estado não sejam objetos de restrição de acesso ou destruição (BRASIL, 2011a). Como princípio norteador, a LAI determina que o acesso público à informação é a regra e o sigilo deve ser a exceção. Em teoria, portanto, o acesso aos documentos de arquivo necessários às investigações das comissões da verdade deveria estar garantido e viabilizado pela LAI, salvo exceções.

No relatório final da CNV, por exemplo, a comissão da verdade afirma ter sido determinante para os seus trabalhos que "o processo legislativo que produziu a Lei $n$. 12.528/2011 tenha se dado simultaneamente àquele que 
conduziu à aprovação da Lei n. 12.527/2011, de Acesso à Informação (LAI)" (BRASIL, 2014, p 22). Ao estabelecer que informações ou documentos sobre graves violações de direitos humanos não poderiam ser objeto de restrição, a LAI permitiu que a CNV utilizasse esse dispositivo para recorrer, por exemplo, à decisão das Forças Armadas em não disponibilizar as folhas de alteração dos militares, e fazer prevalecer, junto ao Ministério da Defesa, a interpretação conjunta das duas leis, caracterizando as folhas de alteração como informações administrativas. A CNV ainda afirmou que:

[...] exerceu, por diversas vezes, seu poder de requisição de documentos e informações diretamente aos órgãos e entidades do poder público. Primeiramente, requisitou dados, documentos e informações, ainda que classificados em qualquer grau de sigilo. Tratando-se de material sigiloso, cumpriu a obrigação prevista no artigo 4, parágrafo 2, de não o divulgar ou disponibilizar a terceiros. Requisitou, também, o auxílio de entidades e órgãos públicos para a execução dos objetivos previstos em lei (BRASIL, 2014, p. 44).

Em relação às outras comissões da verdade brasileiras analisadas, não encontramos praticamente menção alguma à LAl nos relatórios finais. Com exceção da Comissão da Verdade do Estado de São Paulo que, ao relatar o acesso aos arquivos do Instituto Médico Legal (IML) e do Instituto de Criminalística do Estado de São Paulo, afirmou ter utilizado a LAI como base aos pedidos de acesso aos documentos (COMISSÃO ESTADUAL DA VERDADE DE SÃO PAULO "RUBENS PAIVA", 2015).

Apesar disso, não podemos afirmar que as comissões da verdade não utilizaram a LAI ao solicitar informações, como percebemos a partir de um e-mail que trocamos com um dos ex-assessores da Comissão da Verdade da Prefeitura de São Paulo, em 30/01/2017, sobre a utilização da lei de acesso à informação nos trabalhos da comissão. Ao explicar que havia um entendimento interno de que os ofícios produzidos pela comissão da verdade deveriam ser expedidos via secretaria executiva, o assessor nos relatou que a comissão, muitas vezes, fez uso dos e-Sic (Sistema Eletrônico do Serviço de Informações ao Cidadão, implementados após a criação da LAI) durante as pesquisas porque esse sistema prevê um prazo de resposta, que não acontecia com os ofícios via 
secretaria executiva ${ }^{5}$. Essa experiência não está relatada no relatório final da Comissão da Verdade da Prefeitura de São Paulo, sendo possível, portanto, que outras comissões da verdade tenham feito uso da LAI, mas não registraram essa experiência no relatório final.

Além do recurso à LAI, observamos na pesquisa a utilização, pelas comissões, de outras leis de acesso no exterior para requisitar informações sobre a ditadura militar brasileira existentes fora do Brasil. No relatório final da CNV, a comissão menciona que requisitou aos Comandos das Forças Armadas informações sobre a participação brasileira na Escola das Américas ${ }^{6}$. Após receber resposta negativa do Exército e respostas incompletas da Marinha e da Aeronáutica, a CNV solicitou as mesmas informações ao Ministério da Defesa dos Estados Unidos com base no Freedom of Information Act (FOIA)7, e recebeu uma lista nominal na qual figuram mais de $\mathbf{3 0 0}$ militares brasileiros (BRASIL, 2014).

Apesar da existência de dispositivos legais para o acesso aos arquivos da ditadura militar, a maioria das comissões da verdade analisadas reportou problemas de acesso legal aos documentos. À exceção da Comissão Estadual da Verdade de Santa Catarina, a Comissão da Verdade da Prefeitura de São Paulo e a Comissão da Verdade da UFES, todas as outras comissões da verdade descreveram situações em que o acesso aos arquivos foi negado ou ignorado. Portanto, das 20 comissões da verdade analisadas, 17 mencionaram essa dificuldade.

O ocultamento, por meio da alegação da destruição dos arquivos, aparece em alguns relatórios finais. Exemplo disso foi na Conclusão n. 5 do relatório final da CNV que confirma a morte e desaparecimento de 434 vítimas da ditadura militar onde se pode ler que "apesar dos obstáculos encontrados na investigação, em especial a falta de acesso à documentação produzida pelas

${ }^{5}$ E-mail de um ex-assessor da Comissão da Verdade da Prefeitura de São Paulo, em correspondência trocada com a autora, entre 27 e 31/01/2017.

${ }^{6}$ Fundada pelos Estados Unidos, em 1946, a Escola das Américas (em inglês, School of the Americas), esteve, inicialmente, localizada no Panamá, e teve a finalidade de formar militares na doutrina de segurança nacional.

7 O Freedom of Information Act (FOIA) é uma lei federal americana, aprovada em 4 de julho de 1966 e vigente desde 5 de julho de 1967. 
Forças Armadas, oficialmente dada como destruída" (BRASIL, 2014, p. 963, grifo nosso).

À Comissão Municipal da Verdade de Guarulhos, o Comando da Aeronáutica também informou que a documentação solicitada havia sido descartada: "Após reiteração da solicitação, informando que tal "descarte" violaria as normas do Controle Nacional de Arquivos e a própria transparência do serviço público", o comando, mesmo assim, não entregou os documentos "demonstrando desapreço institucional e falta de vontade de investigar suas falhas ocorridas durante o regime de exceção" (PREFEITURA DE GUARULHOS, 2015, p. 12).

A dúvida acerca da veracidade sobre a destruição desses arquivos é a ausência dos "termos de destruição", previstos nos Decretos n. 60.417, de 11 de março de 1967, e n. 79.099, de 6 de janeiro de 1977, que regulamentaram a salvaguarda de assuntos sigilosos durante a ditadura militar'. Os "termos de destruição" deveriam ser acompanhados de um inventário atualizado, necessários quando houvesse a eliminação dos chamados "documentos sigilosos controlados", além dos "termos de transferência", caso esses documentos tivessem a custódia transferida. Quando a Comissão Municipal de Guarulhos afirma que não há evidências dessa destruição, ela está se referindo a essa questão.

O relatório final da Comissão Estadual da Verdade da Bahia possui uma seção inteira dedicada ao que não foi possível realizar em função das limitadas condições de trabalho. A maior parte da seção refere-se às dificuldades de localização e acesso aos arquivos, incluindo os arquivos do DOPS-BA, à queima de documentos na Base Aérea de Salvador e à falta de colaboração dos militares. Quanto ao ocultamento de documentos, por meio da alegação da restrição de acesso, a comissão baiana relatou: "A CEV-BA fez várias gestões para obter essas informações e lamenta a atitude dos comandos militares

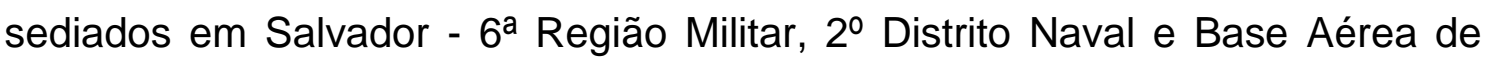

\footnotetext{
8 Para o texto completo dos referidos decretos, ver: http://www.planalto.gov.br/ccivil_03/decreto/1950-1969/D60417.htm e http://www.planalto.gov.br/ccivil_03/decreto/1970-1979/D79099.htm. Acesso em: 12 fev. 2020.
} 
Salvador - que não permitiram acesso dos pesquisadores aos arquivos [...]" (COMISSÃO ESTADUAL DA VERDADE DA BAHIA, 2016, p. 359-360). Exemplo disso foi a resposta do Comando da Marinha que, ao negar acesso às suas dependências, alegando que a comissão da verdade baiana, um órgão estadual, não poderia diligenciar em órgãos sujeitos à administração pública federal, jogando-se por terra qualquer referência à obrigação legal de fornecimento de informações por força da LAI, mas que estaria disponível às solicitações da CNV, um órgão federal:

[...] o Comando da Marinha, enquanto órgão integrante da Administração da Administração Pública Federal, vinculado ao Ministério da Defesa, não está sujeito à legislação estadual, especialmente, o Decreto n. 14.227, de 10 de dezembro de 2012, do Chefe do Poder Executivo do Estado da Bahia. Sem menoscabo às atribuições institucionais dessa Comissão, respaldado nas razões de fato e de direito acima expedidas, participo a Vossa Senhoria a impossibilidade de atender 0 solicitado. Outrossim, tal assertiva não importa em negativa, por parte da Marinha do Brasil, em colaborar com o esforço para a efetivação do direito à memória e à verdade histórica, objetivando à reconciliação nacional, pelo atendimento, de forma ordinária e tempestiva, de todas as solicitações da Comissão Nacional da Verdade (COMISSÃO ESTADUAL DA VERDADE DA BAHIA, 2016, p. 72, grifo nosso).

Se houve mais colaboração à CNV na autorização das diligências por parte dos comandos militares, em razão de seu status de órgão de Estado, a negação da existência de documentos ocorreu da mesma maneira. À título de exemplo, os relatórios finais da CNV e da Comissão Estadual da Verdade do Rio de Janeiro narram uma diligência feita ao Hospital Central do Exército (HCE), no Rio de Janeiro, em outubro de 2014, local onde foi comprovada a morte, sob tortura, de Raul Amaro Nin Ferreira, em 1971. Com o objetivo de atender a uma antiga solicitação, a CNV pediu novamente acesso aos prontuários de ex-presos políticos, cuja existência foi negada pelo diretor do HCE. Semanas depois, o Ministério Público Federal (MPF) realizou uma operação de busca e apreensão de documentos no hospital, em razão de uma denúncia de ocultação de documentos por parte dos funcionários do HCE semanas antes da diligência das comissões da verdade. Nessa operação, o MPF localizou, em uma sala trancada de um prédio anexo ao hospital, prontuários médicos do período da ditadura 
militar, além de sacos plásticos com fichas de pacientes atendidos no mesmo período. Por essa razão, o MPF requereu a instauração de um inquérito policial para apurar o crime de ocultação de documentos.

No desdobramento dessas investigações, o general reformado do Exército e ex-comandante do DOI-CODI do Rio de Janeiro, José Antonio Nogueira Belham, réu na ação do inquérito Rubens Paiva, impetrou um habeas corpus contra o juiz que determinou a busca e apreensão dos documentos no HCE. Mesmo o general não sendo citado nessas investigações, foi concedida uma medida liminar suspendendo, não somente o andamento das investigações sobre a ocultação dos documentos, como qualquer investigação referente ao caso Raul Amaro. Como denuncia a Comissão Estadual do Rio de Janeiro, "com a cobertura do Judiciário, o Exército permanece atento e zela pela impunidade dos crimes praticados por seus agentes" (RIO DE JANEIRO, 2015, p. 208).

A falta de colaboração com os trabalhos das comissões da verdade por meio da restrição de acesso aos arquivos foi também identificada em outras instituições. Por exemplo, ao investigar as graves violações de direitos humanos na Faculdade de Medicina de Ribeirão Preto e no Hospital das Clínicas, a Comissão da Verdade da USP relatou que o acesso aos documentos dessas duas instituições foi negado (UNIVERSIDADE DE SÃO PAULO, 2018).

Engana-se, no entanto, quem acredita que a restrição de acesso aos arquivos e, consequentemente, a sua ocultação deu-se, apenas, por meio de respostas claras como a "impossibilidade de atender o solicitado" ou a "não autorização de acesso". Como foi constatado pela Comissão Estadual da Verdade de Minas Gerais, ao analisar as dificuldades em obter dados e informações em algumas unidades prisionais, a comissão da verdade escreveu o seguinte:

[...] ainda existe um clima de suspeita, receio e medo de tornálos mais acessíveis ao público. O curioso é que as negativas raramente são ditas, explicitadas: elas são sugeridas em documentos não enviados, em telefonemas sem retorno, em reuniões adiadas" (MINAS GERAIS, 2017, p. 294-295).

Nesse sentido, a CNV, ao realizar uma análise qualitativa parcial das respostas do Ministério da Defesa e dos Comandos Militares às suas solicitações, em julho de 2014, aponta que apenas "cerca de um quarto do total 
de ofícios enviados pela CNV foi objeto de atendimento por parte do Ministério da Defesa e das Forças Armadas, e ainda assim, em caráter parcial" (BRASIL, 2014, p. 64). Dos 43 ofícios enviados, 7 deles não receberam resposta. O quadro não mudou quando nova análise qualitativa das respostas do Ministério da Defesa foi realizada próximo ao final dos trabalhos da CNV, em novembro de 2014, sendo minoritária a parcela de respostas que renderam resultados objetivos aos trabalhos de investigação da comissão?.

Exemplos dessas tentativas foram encontrados em diversas passagens do relatório final da CNV: ao requisitar informações sobre as Conferências dos Exércitos Americanos (CEA) ao Ministério da Defesa, o comando do Exército respondeu o seguinte à CNV: "não foi possível encontrar as informações que atendam ao solicitado. Tal impossibilidade decorre do longo período de análise em questão (53 anos) e da consequente impossibilidade de localizar documentos [...]" (BRASIL, 2014, p. 228). Ao solicitar acesso ao banco de dados da Secretaria Executiva Permanente da CEA, a CNV relatou que não recebeu resposta.

A Comissão Estadual da Verdade do Paraná também relata ter enviado dois ofícios a então reitora da Universidade Estadual de Londrina (UEL), sendo que o primeiro deles só foi respondido ao final da audiência pública realizada em Londrina, não podendo subsidiar as oitivas da comissão; e o segundo ofício não foi respondido. Por essa razão, a comissão da verdade recomendou que fosse encaminhado o relatório final ao Conselho Universitário da UEL, para o "conhecimento dos fatos ora relatados e providências quanto à obstrução das investigações traduzida no não fornecimento de informações requisitadas [...]" (COMISSÃO ESTADUAL DA VERDADE DO PARANÁ, 2014, sem paginação).

Após a análise dos relatórios finais, constatamos que a maior parte das dificuldades relacionadas ao "acesso legal" dos documentos veio das Forças Armadas, especialmente do Exército.

\footnotetext{
${ }^{9}$ Sobre o diálogo da CNV com as Forças Armadas e o Ministério da Defesa, ver: MEZAROBBA, G. Mentiras gravadas no mármore e verdades perdidas para sempre. Revista Sur, vol. 12, n. 21, ago./2015.
} 


\subsection{A Falta de Gestão Documental: as Dificuldades Quanto ao Acesso Físico e InTELectual aos Arquivos}

À luz das definições de acesso aos arquivos propostas por Taylor (1984), entre as quais estão definidos o acesso físico e intelectual, relacionando-se, respectivamente, às questões de recolhimento e avaliação dos documentos arquivísticos, e aos instrumentos de pesquisa e disponibilização, apresentaremos as dificuldades de acesso aos arquivos relatadas pelas comissões da verdade.

Segundo Taylor (1984), o acesso físico e intelectual aos documentos arquivísticos se relacionam porque dependem inteiramente das operações que envolvem o tratamento documental.

No Brasil, a lei que dispõe sobre a política nacional dos arquivos públicos e privados, a Lei n. 8.159, de 8 de janeiro de 1991, conhecida como Lei de Arquivos, dispõe, em seu Art. $1^{\circ}$ :

Art. 1ㅇ - É dever do Poder Público a gestão documental e a proteção especial a documentos de arquivos, como instrumento de apoio à administração, à cultura, ao desenvolvimento científico e como elementos de prova e informação (BRASIL, 1991, não paginado).

Ainda conforme a Lei, no seu Art. 3 a gestão de documentos é definida como:

Art. $3^{\circ}$ - [...] o conjunto de procedimentos e operações técnicas referentes à sua produção, tramitação, uso, avaliação e arquivamento em fase corrente e intermediária, visando a sua eliminação ou recolhimento para guarda permanente (BRASIL, 1991, não paginado).

É importante ressaltar que a obrigação do Estado na gestão e disponibilização dos documentos públicos já está prevista desde a Constituição de 1988, conforme o Art. 216 e parágrafo $2^{\circ}$ : "Cabem à administração pública, na forma da lei, a gestão da documentação governamental e as providências para franquear sua consulta a quantos dela necessitem." (BRASIL, 1988, não paginado).

Com relação à consulta dos documentos arquivísticos, Belloto (2012) nos lembra que "como os depósitos de arquivos, obviamente, nunca são de livre 
acesso, seu potencial de informações só chega ao usuário via instrumento de pesquisa" (BELLOTO, 2012, p. 179). Recorrendo à Baudot (1970), Bellotto a destaca que uma "massa de informações" contida em um arquivo só é útil a partir da existência de instrumentos de pesquisa que permitem a difusão das informações aos usuários (BELLOTO, 2012, p. 179-180). Ou seja, são os instrumentos de pesquisa que fazem a mediação entre os usuários e as informações contidas nos documentos de arquivo.

Após análise dos relatórios finais, percebemos que a grande maioria das comissões da verdade relatou dificuldades de acesso aos arquivos resultantes da falta de conservação, operações técnicas de tratamento, incluindo a produção de instrumentos de pesquisa e reprodução dos documentos arquivísticos. Dos 20 relatórios finais analisados, 18 deles mencionam entraves resultantes do acesso físico e intelectual aos documentos arquivísticos no curso de suas investigações.

Para identificar essas dificuldades, no entanto, não foi preciso avançar muito nas páginas dos relatórios finais. Ao iniciar a apresentação das atividades desenvolvidas e os resultados produzidos, a Comissão Estadual do Amapá escreveu que "[...] mesmo com todas as dificuldades de pesquisa e coleta de dados e informações, por exemplo, a ausência de um Arquivo Público Estadual [...], a CEV-AP buscou cumprir a missão de investigar o passado e romper com o silêncio" (COMISSÃO ESTADUAL DA VERDADE DO AMAPÁ, 2017, p. 5). A Comissão Estadual da Verdade de Minas Gerais, ao descrever a seção "a pesquisa e seus desafios", justifica que "esse desafio se impôs no processo de reunião de fontes documentais que se encontravam dispersas em acervos com níveis diferentes de organização e preservação" (MINAS GERAIS, 2017, p. 20). Já a Comissão Estadual da Verdade da Paraíba, explica que:

[...] conseguiu resgatar com bastante sacrifício inúmeros documentos que estavam "arquivados" em repartições federais ou estaduais. Tal trabalho demonstrou a pertinácia dos membros da comissão, pois em sua maioria, os arquivos encontram-se desorganizados, faltando documentos, etc. (PARAíBA, 2017, p. 29).

No entanto, as páginas iniciais dos relatórios finais não mencionam apenas dificuldades relacionadas ao recolhimento e falta de organização dos 
acervos. A Comissão da Verdade da USP, que dedicou às fontes documentais todo o Volume 10 do seu conjunto de volumes do relatório final, explica os entraves referentes aos inadequados instrumentos de pesquisa desses acervos: "Uma das maiores dificuldades enfrentadas pelos pesquisadores diz respeito aos mecanismos de busca utilizados para a consulta nesses acervos que, em geral, permitem apenas buscas nominais, de pessoas ou instituições" (UNIVERSIDADE DE SÃO PAULO, 2018, p. 10).

Em referência específica aos acervos das polícias políticas e dos órgãos de repressão e informação da ditadura militar, algumas comissões da verdade relataram dificuldades em acessar essa documentação por falta de organização, apesar das políticas de recolhimento desses acervos terem iniciado há mais de vinte anos. Por exemplo, a Comissão Estadual da Verdade de Minas Gerais alerta que, mesmo após o decreto-lei estadual de 2013, determinando o recolhimento dos arquivos do DOPS/MG ao Arquivo Público Mineiro (APM), não foi possível trabalhá-lo porque, apesar de ser extremamente rico em informações, o acervo ainda não estava sistematizado, "de modo que tal tarefa resta em aberto para pesquisas futuras" (MINAS GERAIS, 2017, p. 182).

A Comissão Estadual da Verdade do Rio de Janeiro, por sua vez, por meio do GT DOPS, realizou diversas oitivas no interior do prédio do antigo Departamento de Ordem Política e Social (DOPS), na cidade do Rio de Janeiro, encontrando uma vasta documentação em estado avançado de deterioração. Após solicitação de parecer técnico do Arquivo Público do Estado do Rio de Janeiro (APERJ) e do Projeto Memórias Reveladas, do Arquivo Nacional, as equipes detectaram documentos que poderiam ser úteis às investigações da comissão da verdade, recomendando a sua higienização para posterior utilização. A comissão da verdade afirma que notificou as instâncias administrativas responsáveis, mas constatou a permanência da documentação nas mesmas condições de abandono. Em nova diligência ao local, anuncia que a documentação foi retirada e levada para local desconhecido (RIO DE JANEIRO, 2015).

As comissões da verdade, sem dúvida, envidaram muitos esforços nas buscas pelos arquivos que pudessem conter informações relevantes às suas 
investigações, incluindo aqueles cuja existência foi dada como destruída. Exemplo disso, a Comissão da Verdade da UFES, na tentativa de localizar os arquivos da ASI/UFES, dificultada pelo incêndio que destruiu grande parte do acervo documental da universidade, em 1999, relata ter realizado um verdadeiro "trabalho arqueológico" nos diversos "arquivos improvisados", tais como "banheiros desativados, que haviam sido convertidos em "arquivos" no prédio da Reitoria, em almoxarifados, embaixo de escadas e em salas desativadas no ginásio de esportes do CEFD [Centro de Educação Física e Desportos]" (UNIVERSIDADE FEDERAL DO ESPÍRITO SANTO, 2016, p. 18).

Já a Comissão da Verdade da UFRN destaca o trabalho de "garimpagem" realizado, "tendo em vista a total desorganização e mau acondicionamento dos acervos históricos das antigas unidades da UFRN e das próprias entidades de representação discente" (UNIVERSIDADE FEDERAL DO RIO GRANDE DO NORTE, 2015, p. 323).

Nesse sentido, a Comissão da Verdade da USP, ao mencionar o trabalho de localização e utilização das fontes documentais, especialmente referentes ao acervo da AESI/USP, queimado com a autorização do próprio reitor da época, Hélio Guerra Vieira, explica que essas fontes são marcadas por dinâmicas próprias, sendo produzidas, em sua maioria, pelos órgãos de segurança e repressão da ditadura militar responsáveis pela difusão de informações para outros órgãos que compunham o complexo sistemas de informações e repressão, onde, ainda, é possível encontrar segunda via de alguns documentos:

Essa peculiaridade da ditadura brasileira, caracterizada pela vasta difusão das informações, permitiu que se encontrassem documentos que haviam sido queimados na sua origem, como aqueles produzidos pela AESI/USP, cujas cópias, enviadas para outros órgãos, foram localizadas no acervo DEOPS, depositadas posteriormente no Arquivo do Estado de São Paulo, Fundo Departamento de Ordem Política e Social (DEOPS), e no Arquivo Nacional, Fundo Serviço Nacional de Informações (SNI)" (UNIVERSIDADE DE SÃO PAULO, 2018, p. 17).

Como sabemos, as investigações das comissões da verdade não utilizaram apenas os arquivos dos órgãos de segurança e repressão da ditadura militar. Foram também pesquisados os arquivos dos serviços funerários e cemitérios, e os arquivos administrativos de órgãos estatais e de empresas 
privadas, aqueles, denominados por González Quintana, como "arquivos convencionais", ou seja, "todos os arquivos" produzidos durante um regime repressor, pois se "os arquivos são um reflexo da sociedade que os produzem", então os "arquivos convencionais" também podem estar "cheios de declarações sobre eventos repressivos que poderiam ser de extraordinária importância quando se procura atribuir responsabilidades ou danos" (QUINTANA, 2009, p. 46-47).

Algumas comissões da verdade, no entanto, não conseguiram acesso aos chamados "arquivos convencionais" em razão da falta de organização. Por exemplo, a Comissão da Verdade da Prefeitura de São Paulo, que realizou um extenso e difícil trabalho de pesquisa nos arquivos dos cemitérios municipais de São Paulo, Serviço Funerário Municipal e Instituto Médico Legal (IML), em busca de informações sobre o sepultamento ilegal de dezenas de militantes políticos, enterrados como indigentes pela administração municipal durante a ditadura militar, a falsificação de nomes e a construção de valas clandestinas, descreve o péssimo estado de conservação dessa documentação e a dificuldade de utilização desses documentos. Ao recomendar a digitalização do acervo do Serviço Funerário do Município, relata que por pouco as pesquisas da comissão da verdade nos acervos da autarquia não foram inviabilizadas: "durante o período de atividade da CMV [Comissão da Memória e Verdade], parte do arquivo foi interditado pela Comissão Interna de Prevenção de Acidentes por ter sido encontrado um escorpião no viaduto" (PREFEITURA DE SÃO PAULO, 2016, p. 285). Ao realizar visitas a diversos cemitérios do município, a Comissão identificou "problemas no registro e no arquivamento da documentação referente à localização e destinação de corpos e restos mortais sepultados nos cemitérios municipais. Esse diagnóstico de desorganização não é recente e se estende também ao Instituto Médico Legal e ao Serviço de Verificação de Óbitos da Capital" (PREFEITURA DE SÃO PAULO, 2016, p. 281). No Cemitério de Vila Formosa, por exemplo, foram encontrados livros de registro em péssimo estado de conservação, com encadernação solta e folhas despedaçadas, muitas vezes impossibilitando a consulta. No Cemitério de Vila Nova Cachoeirinha, a comissão da verdade encontrou sacos de ossada dividindo a sala com os livros de 
registros.

Por fim, quanto à existência de instrumentos de pesquisa, necessários ao acesso "intelectual" proposto por Taylor (1984), algumas comissões da verdade relataram que, mesmo com a presença desses mecanismos de busca nos acervos, o acesso aos arquivos foi dificultado pela falta de padronização desses instrumentos.

A Comissão da Verdade da USP descreveu exaustivamente essas dificuldades, afirmando que a "consolidação das informações é dificultada não apenas pela variedade e falta de padronização de tais documentos, mas também pela cultura de cada unidade ou órgão da Universidade no trato e acesso a eles" (UNIVERSIDADE DE SÃO PAULO, 2018, p. 16). Já no início de suas atividades, em função dos mecanismos de busca que permitiam apenas buscas nominais de pessoas ou instituições, a comissão da verdade precisou elaborar uma extensa lista inicial com aproximadamente 600 nomes de pessoas vinculadas à USP. A comissão da verdade menciona, por exemplo, os processos administrativos da Universidade que não oferecem mecanismos de busca por assunto de qualquer natureza, "levando os pesquisadores a documentos burocráticos individuais, como contratações, contagem de tempo, acumulação de cargos, afastamentos e históricos escolares" (UNIVERSIDADE DE SÃO PAULO, 2018, p. 11).

Quanto às dificuldades mencionadas pela Comissão da Verdade da USP dada a diferença de cultura organizacional de cada unidade ou órgão da Universidade, a comissão descreve como cada faculdade adotou critérios próprios de arquivamento, fazendo com que, a cada unidade, os pesquisadores tivessem que "se adaptar às novas formas de organização que lhes eram apresentadas (UNIVERSIDADE DE SÃO PAULO, 2018, p. 17).

\section{CONSIDERAÇÕES FINAIS}

Desde os anos 1980, com o início das buscas por mortos e desaparecidos políticos, familiares e vítimas da ditadura militar enfrentaram inúmeros obstáculos para a obtenção de informações. A partir da década de 1990, com o 
recolhimento de diversos acervos referentes ao aparato repressivo militar, incluindo os acervos das polícias políticas e dos órgãos de segurança e informação, a disponibilidade de informações sobre a ditadura militar aumentou exponencialmente. Aliado ao acervo documental, a LAI vem regulando, desde 2012, o direito constitucional de acesso à informação pública.

Dada a realidade atual dos arquivos da ditadura militar, no que tange a LAI e o recolhimento dos acervos dos órgãos de segurança e informação, pareceu interessante indagar se as condições necessárias ao desenvolvimento das investigações, pelas comissões da verdade, foram propícias para a conclusão dos trabalhos. Para isso, analisamos as experiências sobre a utilização e acesso aos arquivos relatados nos relatórios finais selecionados.

Entre os 20 relatórios finais selecionados, identificamos que 17 relataram problemas de acesso legal aos documentos arquivísticos, na sua maioria, ocasionados pela falta de colaboração das Forças Armadas. A respeito do acesso físico e intelectual, referente às condições de preservação e organização dos documentos, apenas um relatório final não apontou dificuldades nesse sentido.

Apesar do processo de abertura dos arquivos da ditadura militar, por meio de legislação que permitiu o recolhimento dos acervos dos órgãos de repressão aos arquivos públicos, é possível constatar que, em muitos casos, esses documentos ainda não foram organizados e disponibilizados em condições adequadas para a pesquisa. Quanto ao acesso legal, apesar de a LAI determinar que arquivos que versam sobre graves violações de direitos humanos não podem ser objeto de restrição, parece que, em relação aos trabalhos das comissões da verdade analisadas, esse dispositivo tem sido ignorado. Adicionado a isso, o recorrente discurso oficial da inexistência dos arquivos, baseado na eliminação dos documentos, que nunca é provada.

Tais dificuldades, decorrentes da negação da existência dos arquivos da ditadura militar e o seu ocultamento, por meio da restrição de acesso ou alegação de destruição, como um modus operandi de resposta oficial às solicitações, ocasionam uma "falta" ou "ausência" desses arquivos. Segundo a historiadora e psicanalista Elizabeth Roudinesco, "o poder do arquivo é tanto 
mais forte quanto mais ausente for o arquivo" (ROUDINESCO, 2006, p. 7). Nesse sentido, ressaltamos a afirmação da Comissão da Verdade da UnB sobre as consequências da inexistência dos arquivos da Polícia Federal, que configuram em um "verdadeiro sequestro da memória sobre a ditadura, especialmente no caso da UnB [...]" (UNIVERSIDADE DE BRASÍLIA, 2015, p. 26-27).

Sobre a "falta" desses arquivos e a "ausência" de respostas às vítimas e familiares de mortos e desaparecidos políticos, e às investigações sobre as violações de direitos humanos, lembramos o que escreveu a Comissão da Verdade da USP:

[...] cada vez que, diante de uma solicitação de informação sobre uma possível perseguição, não se esclarece o fato ocorrido, a vítima é privada de ver sua real perseguição, sempre camuflada por justificativas administrativas. Repete-se 0 passado utilizando-se a mesma estratégia, por meio do mesmo documento, com os mesmos carimbos e assinaturas. O sujeito, vítima de perseguição no passado, torna-se vítima novamente" (UNIVERSIDADE DE SÃO PAULO, 2018, p. 13).

\section{REFERÊNCIAS}

ARQUIVO NACIONAL. Dicionário de Terminologia Arquivística. Rio de Janeiro: Arquivo Nacional, 2005.

ARQUIVO PÚBLICO DO DISTRITO FEDERAL. Revista Quadrilátero, Brasília, v. 1, n. 1, p. 1-130, mar./ago. 1998.

BAUDOT, M. Les instruments de recherche. In: Manuel d'archivistique. Paris: Association des Archivistes Français, 1970.

BELLOTTO, H. Arquivos permanentes: tratamento documental. Rio de Janeiro: Editora FGV, 2012.

BRAHM, E. What is a Truth Commission and Why Does it Matter? Peace \& Conflict Review, v. 3, n. 2, p. 1-14, 2009.

BRASIL. [Constituição (1998)]. Constituição da República Federativa do Brasil de 1988. Brasília: Presidência da República, 1988.

BRASIL. Lei n. 8.159, de 8 de janeiro de 1991. Dispõe sobre a política nacional de arquivos públicos e privados e dá outras providências. Diário Oficial da República: Brasília, 9 jan. 1991. 
BRASIL. Lei n. 12.527, de 18 de novembro de 2011. Regula o acesso a informações previsto no inciso XXXIII do art. $5^{\circ}$, no inciso II do $\S 3^{\circ}$ do art. 37 e no $\S 2^{\circ}$ do art. 216 da Constituição Federal; altera a Lei ํo 8.112, de 11 de dezembro de 1990; revoga a Lei no 11.111, de 5 de maio de 2005, e dispositivos da Lei oㅡ 8.159, de 8 de janeiro de 1991; e dá outras providências. Diário da União, Brasília, 2011a . Disponível em: http://www.planalto.gov.br/ccivil_03/_ato2011-2014/2011/lei//12527.htm. Acesso em: 05 mai. 2018.

BRASIL. Lei n. 12.528, de 18 de novembro de 2011. Cria a Comissão Nacional da Verdade no âmbito da Casa Civil da Presidência da República. Diário da União, Brasília, 2011b. Disponível em:

http://www.planalto.gov.br/ccivil_03/_ato2011-2014/2011/lei//12528.htm. Acesso em: 05 mai. 2018.

BRASIL. Relatório/Comissão Nacional da Verdade. Brasília: Comissão Nacional da Verdade, 2014. 976p. (Relatório da Comissão Nacional da Verdade; volume 1).

CHAPMAN, A.; BALL, P. The truth of truth commissions: comparative lessons from Haiti, South Africa, and Guatemala. Human Rights Quarterly, v. 23, n. 1, feb. 2001, p. 1-43.

COMISSÃO Estadual da Verdade do Amapá "Francisco das Chagas Bezerra Chaguinha". Relatório Final. Macapá, 2017. 84p.

COMISSÃO Estadual da Verdade da Bahia. Relatório de Atividades: agosto 2013/ abril 2016. Vol. I. Salvador, 2016. 828p.

COMISSÃO Estadual da Verdade do Paraná "Teresa Urban". Relatório Final. Curitiba, 2014. 637p.

COMISSÃO Estadual da Verdade de São Paulo "Rubens Paiva". Relatório Final. São Paulo, 2015. 1912p. (Relatório da Comissão Estadual da Verdade de São Paulo "Rubens Paiva"; Tomo I: Recomendações Gerais e Recomendações Temáticas).

CÔRBO; D. Comissão da Verdade: os documentos e a validez do discurso. 2013. Dissertação (Mestrado em Ciência da Informação) - Programa de PósGraduação em Ciência da Informação, Universidade Federal do Rio de Janeiro; Instituto Brasileiro de Informação em Ciência e Tecnologia. Rio de Janeiro, 2013.

CÔRBO, D.; LIMA, C. Comissão da Verdade: os documentos e a verdade. In: ENCONTRO NACIONAL DE PESQUISA EM CIÊNCIA DA INFORMAÇÃO, 14., 2013, Florianópolis. Anais [...] Florianópolis: UFSC, 2013.

CÔRBO, D.; PIMENTA, R. O documento como objeto e elo interdisciplinar na ciência da informação: o relatório final da comissão nacional da verdade e seus 
efeitos sociais. In: ENCONTRO NACIONAL DE PESQUISA EM CIÊNCIA DA INFORMAÇÃO, 17., 2016, Salvador. Anais [...] Salvador: UFBA, 2016.

HAYNER, P. Unspeakable Truths: transitional justice and the challenge of truth commissions. London, Routledge, 2011. 356p.

HOLLANDA, C. B. de. Direitos humanos e democracia: a experiência das comissões da verdade no Brasil. Revista Brasileira de Ciências Sociais (online), v. 33, n. 96, p. 1-18, 2018.

ISHAQ, V. Os acervos governamentais sobre a repressão política (1964-1985) no Arquivo Nacional: acesso à informação e pesquisa. In: ROCANGLIO, C.; SIMEÂO, E. Gestão da memória: diálogos sobre políticas de informação, documentação e comunicação para a UnB. Brasília: Editora UnB, 2016, p. 113128.

JOFFILY, M. Direito à informação e direito à vida privada: os impasses em torno do acesso aos arquivos da ditadura militar brasileira. Estudos

Históricos, v. 25, n. 49, jan./jun. 2012, p. 129-148.

JONES, B.; OLIVEIRA, I. Truth Commission Archives as 'New Democratic Spaces'. Journal of Human Rights Practice, v. 8, n. 1, p. 6-24, 2016.

MINAS GERAIS. GOVERNO DO ESTADO. Comissão Estadual da Verdade de Minas Gerais. Relatório/Governo do Estado. Belo Horizonte: COVEMG, 2017. 337p.

PARAÍBA. COMISSÃO ESTADUAL DA VERDADE E DA PRESERVAÇÃO DA MEMÓRIA DO ESTADO DA PARAÍBA. Relatório Final. João Pessoa: A União, 2017, 748p.

PIMENTA, R. A rede informacional franco-brasileira durante a ditadura militar no Brasil: o caso dos arquivos da CFDT. In: ENCONTRO NACIONAL DE PESQUISA EM CIÊNCIA DA INFORMAÇÃO, 14., 2013, Florianópolis. Anais [...] Florianópolis: UFSC, 2013.

PREFEITURA DE GUARULHOS. Comissão da Verdade do Município de Guarulhos. Guarulhos: Prefeitura de Guarulhos, 2015. 15p.

PREFEITURA DE SÃO PAULO. Relatório: Comissão da Memória e Verdade da Prefeitura de São Paulo. São Paulo: Prefeitura de São Paulo, 2016. 396p.

QUINTANA, A. G. Archival policies in the protection of human rights. Paris: UNESCO, 2009.

RIO DE JANEIRO. Comissão Estadual da Verdade do Rio de Janeiro.

Relatório Final. Rio de Janeiro: CEV-Rio, 2015. 456p. 
RODRIGUES, G. M. Legislação de acesso aos arquivos no Brasil: um terreno de disputas políticas pela memória e pela história. Acervo, Rio de Janeiro, v. 24, n. 1, p. 257-285, 2011.

ROUDINESCO, E. A análise e o arquivo. Rio de Janeiro: Jorge Zahar Ed., 2006.

TAYLOR, H. A. Archival services and the concept of the user: a RAMP study. Paris: Unesco, 1984.

THIESEN, I.; RODRIGUES, G. M.; FROTA, M. G. da C.; ALMEIDA, P. C. Ciência da informação, história e política. Pesquisa Brasileira em Ciência da Informação e Biblioteconomia, v. 12, n. 2, 2017, p. 360-378.

UNIVERSIDADE DE BRASÍLIA. Relatório da Comissão Anísio Texeira de Memória e Verdade da Universidade de Brasília. Brasília: FAC-UnB, 2016.

UNIVERSIDADE DE SÃO PAULO. Comissão da Verdade da Universidade de São Paulo (USP). Relatório Final. São Paulo, 2018. 51p.

UNIVERSIDADE FEDERAL DO ESPÍRITO SANTO. Relatório Final Comissão da Verdade. Vitória: Ufes/Supecc, 2016. 192p.

UNIVERSIDADE FEDERAL DO RIO GRANDE DO NORTE. Comissão da Verdade da UFRN [recurso eletrônico]: relatório final. Natal: EDUFRN, 2015. 490p.

\title{
DENIAL, CONCEALING, AND (LACK) OF ARCHIVES MANAGEMENT: ARCHIVAL ACCESS IN THE FINAL REPORTS OF TRUTH COMMISSIONS IN BRAZIL
}

\begin{abstract}
Introduction: Truth commissions have been considered one of the most important mechanisms related to investigations into human rights violations and their work relies heavily on access to large amounts of archival documents. Objective: This article analyzes the archival research conditions by truth commissions by analyzing the access processes reported in the final reports. Methodology: It was carried out a survey of the truth commissions installed in Brazil between 2012 and 2018, and selected those which published their final reports and, after, those which presented the difficulties of accessing archives. Results: Arranged according to Taylor's (1984) conception of access, it was found that truth commissions in Brazil faced difficulties of legal, physical and intellectual access to archives, resulting from a lack of collaboration, especially from the Armed Forces, and the precarious conditions of preservation and finding aids. Conclusions: It concludes that, in spite of the greater liberality of access to archives, from the 1990s onwards, due to the Law of Archives and by specific legislation that led to the accession of the archives of the repressive regime, and, in 2011, the promulgation of the Access to Information law (LAI), the archival research conditions on the Brazilian military
\end{abstract}



Taylor.

Descriptors: Brazilian Military Dictatorship. Truth Commissions. Access.

\title{
RESTRICCIÓN, OCULTAMIENTO Y (AUSENCIA DE) ADMINISTRACIÓN DOCUMENTAL: EL ACCESO A LOS ARCHIVOS EN LOS INFORMES FINALES DE LAS COMISIONES DE LA VERDAD EN BRASIL.
}

\begin{abstract}
RESUMEN
Introducción: Las comisiones de la verdad han sido consideradas uno de los dispositivos más importantes relacionados con las investigaciones sobre violaciones de derechos humanos, su trabajo depende principalmente del acceso a grandes cantidades de documentos de archivo. Objetivo: Este artículo analiza las condiciones de investigación a los documentos de archivo por las comisiones de la verdad, mediante el análisis de los procesos de acceso descrito en los reportes finales. Metodología: Fue realizado un levantamiento de las comisiones de la verdad establecidas en Brasil entre 2012 y 2018, en seguida, fueron seleccionadas aquellas que divulgaron sus informes finales, los cuales presentaron dificultades de acceso a los archivos. Resultados: Agrupados de acuerdo con los conceptos de acceso de Taylor (1984) se constató que, las comisiones de la verdad en Brasil, enfrentan dificultades de acceso legal, físico e intelectual a los archivos, todo esto derivado de la falta de colaboración especialmente de las Fuerzas Armadas y de las precarias condiciones de preservación de los documentos, así como ausencia de instrumentos de investigación. Conclusiones: Se concluye que, a pesar de tener mayor libertad de acceso a los archivos a partir de 1990, debido a la Ley de Archivos y por la legislación específica que derivó en la recaudación de los acervos de los órganos de representación, así como, (en 2011) la promulgación de la Ley de Acceso a la Información (LAI); las condiciones de investigación documental sobre la dictadura militar brasileña (1964-1985) se consideran aún precarias en las tres dimensiones resaltadas por Taylor.
\end{abstract}

Descriptores: Dictadura militar brasileña. Comisiones de la verdad. Acceso.

Recebido em: 19/03/2019

Aceito em: 20/02/2020 